Glover, R. E. (1952). J. gen. Microbiol. 6, 251-260.

\title{
The Growth of Mycobacterium tuberculosis and Myco- bacterium johnei in a Modification of Dubos Medium
}

\author{
By R. E. GLOVER \\ Department of Veterinary Pathology, University of Liverpool
}

SUMMARY : Rapid multiplication of Mycobacterium tuberculosis can be obtained in Dubos medium modified by the addition of an iron salt and by the replacement of albumin fraction $\mathrm{V}$ by the supernatant fraction of 'Liquoid'-treated bovine serum.

Certain strains of $M$. johnei can be trained to grow in this medium enriched with a glycerol extract of $\boldsymbol{M}$. phlei.

The success achieved in growing Mycobacterium tuberculosis in liquid medium (Dubos \& Davis, 1946) has aroused interest in the possibility of growing $M$. johnei in this fluid or similar media, modified to contain the essential growth-promoting substances for these organisms. So far no success has been achieved (Davis \& Dubos, 1948; Taylor, 1950).

The combination of $T$ ween 80 and bovine albumin fraction $V$ has certain disadvantages which are not completely overcome by modifications introduced by Dubos and his co-workers (Dubos, 1947; Dubos \& Middlebrook, 1948; Davis \& Dubos, 1948). When added to the rest of the medium, the water soluble lipids selected by Dubos acquire growth-inhibiting properties on standing for several weeks; in consequence, it is necessary to use freshly prepared solutions. In addition, fraction $\mathrm{V}$ bovine albumin on incubation with Tween $\mathbf{8 0}$ may give rise to toxic substances which are related to the lipase content of the serum (Davis \& Dubos, 1948). To some extent this effect can be reduced by heating albumin solution for $30 \mathrm{~min}$. at $56^{\circ}$ to destroy most of the lipolytic activity.

In the course of experiments to find a substitute for fraction $V$ it was found that Dubos medium without albumin, but enriched with serum treated with 'Liquoid' (Na polyanethol sulphonate; Roche Products Ltd.) was suitable for the cultivation of the tubercle bacillus and that, with certain modifications, this medium also grew M. johnei. As any new medium incapable of supporting the growth of the tubercle bacillus was unlikely to be of value for $M$. johnei, all trials were run in parallel with a strain of $\boldsymbol{M}$. tuberculosis var. bovis which was regarded as an appropriate control test organism.

\section{METHODS}

Medium. The basic medium containing asparagine as a source of nitrogen was, with some minor modifications, that of Dubos (1947). Tween 80 was increased from 0.05 to $0.1 \%$, Vegex extract of yeast was replaced by Yeastrel (Paterson \& Winmill, 1950), and $\mathbf{0 . 0 0 2} \%$ of iron ammonium citrate was added.

In the preliminary experiments, after the addition of the Tween 80 , the salt 
solution was distributed in $\mathbf{5 . 0} \mathrm{ml}$. amounts in McCartney bottles and autoclaved at $15 \mathrm{lb}$./sq.in. for $10 \mathrm{~min}$. Sterile glucose Yeastrel solution and fraction $V$ albumin or Liquoid-treated serum, sterilized by filtration through a Seitz EK pad, were added before use. Later it was found that better growth was obtained when the medium was sterilized by filtration. Modifications necessary for the growth of $M$. johnei will be described in the relevant sections of the paper.

Cultures. Two human strains of $M$. tuberculosis, one of which was $\mathbf{H 3 7} \mathbf{R v}$, two bovine strains and one avian strain were used; all were fully virulent for the appropriate laboratory animals. Eight strains of $M$. johnei were available. Cultures in Dubos medium were started by seeding a well-dispersed saline suspension of a young culture from solid medium. Subcultures were made by transferring about $0 \cdot 1-5 \cdot 0 \mathrm{ml}$. to fresh medium.

Estimation of growth. The density of the growth was estimated by a sensitive photoelectric densitometer similar to that described by Belyavin, Westwood, Please \& Smith (1951). Standard tubes containing $1 \cdot 0,0 \cdot 9,0 \cdot 8,0 \cdot 7,0 \cdot 6,0 \cdot 5$, $0 \cdot 4,0 \cdot 3,0.2$ and $0.1 \mathrm{mg} . / \mathrm{ml}$. of a well-dispersed culture of $\boldsymbol{M}$. tuberculosis from solid media in normal saline were preserved with $0.2 \%$ formalin. The sensitivity of the galvanometer was adjusted so that mid-scale deflexion was obtained with $0.5 \mathrm{mg} . / \mathrm{ml}$. The slight colour of Dubos medium enriched with serum does not materially alter the basic readings.

\section{RESULTS}

\section{Properties of Liquoid-treated serum}

Liquoid, first used as a powerful anti-coagulant, was subsequently found to depress the normal bactericidal properties of fresh blood and thus encourage the growth of small numbers of organisms. It has been suggested that this action may be related to an inactivation of complement (van der Holden, 1940; Stuart, 1948), to the destruction of bactericidal substances in the blood (von Haebler \& Miles, 1938; Hoare, 1939), to the paralysis of leucocytes (Allgöwer, 1949), or to an effect on other growth-inhibiting substances in the blood.

To prepare the serum fraction for the replacement of albumin fraction $\mathbf{V}$ in Dubos medium, Liquoid was added to the serum. Suitable concentrations produced a fine precipitate; the turbidity was measured by the densitometer, and successive batches of the same sample of serum gave identical readings. Other samples, from different animals of the same species, or from the same animal at different times, often gave readings indicating a higher or lower concentration of particulate matter. These differences were also demonstrated by centrifuging the treated serum at 5000 r.p.m. for $10 \mathrm{~min}$. and weighing the sediments.

When similar samples of the same serum batch were treated with decreasing amounts of Liquoid, the quantity of precipitate steadily declined. No difference was detected in samples treated with 2,1 and $0.8 \mathrm{mg} . / \mathrm{ml}$. serum, but with less the turbidity fell until, with an amount of $0.05 \mathrm{mg} . / \mathrm{ml}$., no detectable reading 
was observed and only a trace of sediment was produced on centrifugation. Serum from clotted blood yielded heavier sediments than citrated or oxalated plasma, indeed many samples treated with citrate gave only a trace of precipitate with the maximum quantity of Liquoid. This suggested that calcium was essential for the formation of the precipitate. Chorine (1941) postulated that Liquoid acts as a protein precipitant; he showed that if plasma is treated with Liquoid and the precipitate removed, no further deposit was produced by the addition of more Liquoid: however, with the addition of calcium chloride, a second precipitate was formed which was also protein in nature. The need for calcium was shown in the following manner. Samples of serum and citrated plasma from the same guinea-pig were treated with $1 \mathrm{mg}$. Liquoid $/ \mathrm{ml}$. In the serum a heavy precipitate formed, whereas in the plasma only a slight haziness developed. The addition of $\mathrm{CaCl}_{2}$ to the Liquoid plasma to make a dilution of $1 / 1000$ resulted in a heavy precipitate which is probably produced by an interaction of some plasma constituent, the Liquoid and the calcium ions, and is not a component of the plasma deposited on an insoluble calcium-Liquoid derivative because, in the absence of plasma or serum, calcium salts do not form a precipitate with Liquoid.

The amount of precipitate was dependent on the hydrogen-ion concentration of the serum; it was small in samples at $\mathrm{pH} 7 \cdot 8$ or over, even in the presence of calcium, but increased when the serum was acidified. A very heavy precipitate with a nearly water-clear supernatant was produced by mixing serum, 1/1000 calcium chloride and 1/1000 glacial acetic acid in equal quantities. Such supernatants did not contain the growth-promoting factors necessary for the Tween 80 medium.

Sediment from Liquoid-treated plasma or serum was only partially soluble in water or normal saline, and it became increasingly insoluble if it was not removed as soon as possible. It was readily soluble in $1 / 1000$ sodium carbonate.

In view of the statement by Davis \& Dubos (1946) that the albumin constituent of serum is the component which protects acid-fast organisms against the toxic action of Tween 80, the sediments and supernatant fractions of Liquoid-treated serum were examined. To obtain a sediment free from the constituents of the supernatant portion, the precipitate produced by the action of $1 \mathrm{mg}$. Liquoid $/ \mathrm{ml}$. serum in the presence of an equal amount of calcium chloride (1/1000) was washed three times with a mixture of $10 \mathrm{ml}$. distilled water containing $1 \mathrm{mg} . / \mathrm{ml}$. Liquoid, $5 \mathrm{ml}$. of $1 / 1000$ calcium chloride and $5 \mathrm{ml}$. of 1/1000 glacial acetic acid in which the sediment was completely insoluble. After the final washing, the sediment was dissolved in 1/1000 sodium carbonate solution and a rough analysis of the two portions gave the following results :
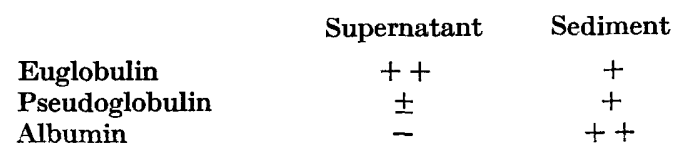

It is clear that all the albumin is concentrated in the sediment. It will be shown that the supernatant portion was active in promoting the growth of 
acid-fast bacilli and the sediment was valueless. It appears, therefore, that the stimulation of growth may be dependent on the euglobulin and not on the albumin. The Liquoid-treated fraction of serum added to the Tween medium is the supernatant portion after removal of the precipitate.

\section{The growth of Mycobacterium tuberculosis in modified Dubos medium}

In Tween medium containing fraction $\mathrm{V}$ albumin, a human strain such as $\mathrm{H} 37 \mathrm{Rv}$ will produce a distinct haziness after $48 \mathrm{hr}$. at $37^{\circ}$. Growth increases progressively, but the maximum density is not reached before the tenth day. In Tween medium enriched with Liquoid-treated bovine serum (L.T.S.) and containing a small quantity of ferrous ammonium citrate, the organisms multiply more rapidly and the density of a 4-day culture is about equal to that of a 7-day growth in the conventional Dubos solution (Table 1).

Table 1. Comparison of the effect of fraction $V$ albumin and Liquoidtreated serum on the growth of Mycobacterium tuberculosis

\begin{tabular}{|c|c|c|c|c|c|c|c|c|c|c|}
\hline & \multicolumn{10}{|c|}{ Growth (mg./ml.) } \\
\hline & \multicolumn{5}{|c|}{$\begin{array}{c}\text { Base + fraction V albumin } \\
\text { Days }\end{array}$} & \multicolumn{5}{|c|}{$\begin{array}{c}\text { Base }+ \text { Liquoid-treated serum } \\
\text { Days }\end{array}$} \\
\hline & 3 & 4 & 5 & 7 & 10 & 3 & 4 & 5 & 7 & 10 \\
\hline Human & $0 \cdot 1$ & 0.3 & $0 \cdot 3$ & 0.5 & 0.8 & 0.2 & 0.5 & $0 \cdot 6$ & 0.8 & $1 \cdot 0$ \\
\hline Bovine & - & tr. & $0 \cdot 1$ & 0.3 & 0.5 & tr. & 0.2 & 0.2 & $0 \cdot 5$ & 0.7 \\
\hline
\end{tabular}

Experiments were made to find the optimum amount of Liquoid required to give the most active supernatant fluid. The proportions varied from 5 to $0.05 \mathrm{mg}$. $/ \mathrm{ml}$., always in the presence of $1 / 1000$ calcium chloride. The most rapid growth occurred in the range $2-0.5 \mathrm{mg} . / \mathrm{ml}$.; from this point the quantity of insoluble material steadily decreased, as shown in the previous section, and the supernatant fluids became less active. With concentrations of Liquoid in excess of $2 \mathrm{mg}$./ml., growth was delayed and partly inhibited. This was not due to an increase in the precipitate, as further additions of Liquoid to the supernatant fluid from serum treated with $2 \mathrm{mg}$. $/ \mathrm{ml}$. failed to produce an additional precipitate. It is probable, therefore, that Liquoid in excess of $2 \mathrm{mg} . / \mathrm{ml}$. has a direct inhibitory action on growth (Table 2). The amount finally selected was $1 \mathrm{mg} . / \mathrm{ml}$.

Some latitude is permissible in the proportion of L.T.s. which can be added to the basic medium as growth of all three types of tubercle bacilli was obtained with amounts varying from 2 to $20 \%$; the most consistent results were obtained with $5 \%$ and this amount was finally adopted. The sediment from Liquoidtreated serum, redissolved in weak alkali, neutralized, and added to Tween medium in the same proportion as the L.T.S., completely inhibited growth of a human strain.

Various types of serum were fractionated with Liquoid and tested for growth-promoting properties. Bovine serum gave the best results, but good 
Table 2. Growth of Mycobacterium tuberculosis in basic medium with

Liquoid-treated bovine serum

\begin{tabular}{|c|c|c|c|}
\hline \multirow[b]{2}{*}{$\begin{array}{l}\text { Liquoid (mg./ml.) } \\
\text { added to serum }\end{array}$} & \multicolumn{3}{|c|}{$\begin{array}{c}\text { Growth (mg./ml.) after } 10 \text { days } \\
\text { with strain }\end{array}$} \\
\hline & $\mathrm{H}$ & B & A \\
\hline $5 \cdot 0$ & 0.3 & $0 \cdot 1$ & $0 \cdot 2$ \\
\hline $2 \cdot 0$ & 1.0 & 0.7 & $1 \cdot 1$ \\
\hline $1 \cdot 0$ & 0.9 & 0.8 & $1 \cdot 0$ \\
\hline 0.5 & 0.8 & $0 \cdot 6$ & $1 \cdot 0$ \\
\hline 0.2 & 0.4 & $0 \cdot 2$ & $0 \cdot 8$ \\
\hline $0 \cdot 1$ & 0.2 & $0 \cdot 1$ & $0 \cdot 5$ \\
\hline 0.05 & 0.2 & tr. & 0.2 \\
\hline None & - & - & - \\
\hline $\mathbf{H}=\mathbf{h u m}$ & $\begin{array}{l}\mathrm{B}= \\
\text { ols a }\end{array}$ & $\begin{array}{l}A= \\
1 .\end{array}$ & \\
\hline
\end{tabular}

cultures were obtained with L.T.s. from horse, sheep and rabbit sera, although longer incubation was required. The difference may be due to variations in aggregation of the insoluble fraction since, even in the presence of calcium chloride, the amount of precipitate, particularly in horse sera, was less than in bovine sera.

In an article on Tween medium (Dubos \& Davis, 1946), it was emphasized that no systematic investigation of the constituents of the basal medium had been attempted. Later, Dubos (1947) devised a modified solution containing ammonium sulphate which was used for determining the effect on growth of various combinations of glucose, casein, ferric chloride and Tween 80 . It seemed desirable to ascertain whether variations in the amount of asparagine, glucose and Tween 80 , in the presence of L.T.s., would have any material effect on the rate of growth. Table 3 clearly indicates that there is a critical level for each constituent. The optimum amounts were $0.1-0.5 \%$ glucose, $0.1-0.5 \%$ asparagine, and $0 \cdot 02-0 \cdot 1 \%$ Tween 80 .

Table 3. Effect of additions to basic medium on growth of Mycobacterium tuberculosis (human)

\begin{tabular}{|c|c|c|c|}
\hline $\begin{array}{l}\text { Glucose } \\
\%(w / v)\end{array}$ & $\begin{array}{c}\text { Asparagine } \\
\%(w / v)\end{array}$ & $\begin{array}{c}\text { Tween } 80 \\
\%(v / v)\end{array}$ & $\begin{array}{l}\text { Growth }(\mathrm{mg} . / \mathrm{ml} .) \\
\text { at } 10 \text { days }\end{array}$ \\
\hline 0.05 & $0 \cdot 1$ & $0 \cdot 1$ & $0 \cdot 2$ \\
\hline 0.1 & $0 \cdot 1$ & 0.1 & $0 \cdot 6$ \\
\hline $0 \cdot 2$ & $0 \cdot 1$ & $0 \cdot 1$ & 0.7 \\
\hline 0.5 & $0 \cdot 1$ & 0.1 & 0.7 \\
\hline 1.0 & 0.1 & $0 \cdot 1$ & $0 \cdot 4$ \\
\hline 0.2 & 0.02 & $0 \cdot 1$ & 0.2 \\
\hline $0 \cdot 2$ & 0.05 & $0 \cdot 1$ & $0 \cdot 6$ \\
\hline 0.2 & $0 \cdot 1$ & $0 \cdot 1$ & $0 \cdot 8$ \\
\hline 0.2 & $0 \cdot 2$ & $0 \cdot 1$ & $0 \cdot 8$ \\
\hline 0.2 & 0.5 & $0 \cdot 1$ & 0.7 \\
\hline 0.2 & $0 \cdot 1$ & 0.01 & 0.2 \\
\hline 0.2 & $0 \cdot 1$ & 0.02 & $0 \cdot 6$ \\
\hline $0 \cdot 2$ & 0.1 & 0.05 & $0 \cdot 6$ \\
\hline 0.2 & 0.1 & $0 \cdot 1$ & 0.7 \\
\hline 0.2 & $0 \cdot 1$ & 0.2 & 0.3 \\
\hline
\end{tabular}

Figures in black indicate amount selected for final medium. 
The original Tween formula contained no added iron salts, but in a modified medium, in which the source of nitrogen is ammonium sulphate, a trace of ferric chloride $(0.001 \% \mathrm{w} / \mathrm{v})$ was essential to obtain rapid growth of $\boldsymbol{M}$. tuberculosis (Dubos, 1947). It appears that in this medium the Vegex had been omitted. It is possible that in the original Dubos solution the Vegex provided sufficient iron to initiate and maintain growth. It was found, however, that even with the addition of Yeastrel an iron salt greatly improved growth in L.T.S. medium. Table 4 shows the results obtained with decreasing amounts of iron ammonium citrate, and indicates the superiority of this modification in enhancing not only the speed of growth but also the maximum concentration. The amount finally selected was $\mathbf{0 . 0 2} \mathrm{mg}$. iron salts to $1 \mathrm{l}$. of medium.

Table 4. Effect of ferrous ammonium citrate on growth of Mycobacterium tuberculosis (human)

\begin{tabular}{|c|c|c|c|}
\hline \multirow{2}{*}{$\begin{array}{c}\text { Ferrous ammonium } \\
\text { citrate } \\
(\mathrm{mg} . / 100 \mathrm{ml} .)\end{array}$} & \multicolumn{3}{|c|}{ Growth (mg./ml.) in days } \\
\hline & 4 & 7 & 10 \\
\hline 0.05 & 一 & 0.1 & $0 \cdot 3$ \\
\hline 0.01 & tr. & 0.5 & 0.8 \\
\hline 0.005 & 0.3 & 0.8 & $1 \cdot 0$ \\
\hline $0 \cdot 002$ & 0.3 & 0.8 & $1 \cdot 1$ \\
\hline 0.0005 & 0.2 & 0.7 & 0.9 \\
\hline $0 \cdot 0001$ & $0 \cdot 1$ & 0.4 & 0.7 \\
\hline None & 0.2 & 0.4 & $0 \cdot 7$ \\
\hline
\end{tabular}

Figures in black indicate amount selected for final medium. Symbols as in Table 1.

Table 5. Growth of Mycobacterium tuberculosis $(\mathrm{mg} . / \mathrm{ml}$.) in basic medium plus glycerol

\begin{tabular}{|c|c|c|c|}
\hline \multirow{2}{*}{$\begin{array}{c}\text { Glycerol } \\
(\mathrm{v} / \mathrm{v})\end{array}$} & \multicolumn{3}{|c|}{ Strain } \\
\hline & $\mathbf{H}$ & $\mathbf{B}^{1}$ & $\mathbf{B}^{2}$ \\
\hline 0.5 & $1 \cdot 0$ & 0.8 & 0.2 \\
\hline 1.0 & $1 \cdot 1$ & $0 \cdot 7$ & tr. \\
\hline $2 \cdot 0$ & $1 \cdot 0$ & $0 \cdot 3$ & 一 \\
\hline $4 \cdot 0$ & 0.2 & tr. & - \\
\hline $7 \cdot 0$ & tr. & tr. & - \\
\hline None & 0.9 & $0 \cdot 6$ & 0.5 \\
\hline
\end{tabular}

$\mathbf{H}=$ human; $\mathbf{B}^{1}=$ bovine from $5 \%$ glycerol medium; $\mathbf{B}^{2}=$ recently isolated bovine. Symbols as in Table 1 .

Dubos \& Davis (1946) noted that the addition of a small amount of glycerol $(0.5 \%)$ had no appreciable effect on the growth-supporting properties of Tween medium, but that when the glycerol was increased to $5 \%$ multiplication was poor or completely inhibited according to the purity of the glycerol. The absence of glycerol is of little importance when the tubercle bacillus is being studied, but it might be necessary for the growth of $M$. johnei for which Taylor (1950) has shown that in egg media the optimum concentration of glycerol is $4 \%$.

In order to examine the influence of glycerol on growth of $M$. tuberculosis in Tween 80 plus L.T.s., various concentrations of a commercial product were tested (Table 5). The growth of the human strain was accelerated by amounts 
up to $2 \%$, and a bovine strain, which had been maintained on $5 \%$ glycerol egg medium, by $1 \%$, but larger amounts had an increasing inhibitory action. A bovine strain recently isolated from milk was much more sensitive to glycerol and was completely inhibited by quantities in excess of $1 \%$. This suppression of growth may have been due, however, to the direct action of the glycerol on a dysgenic strain and not to the effect of glycerol on Tween $\mathbf{8 0 .}$

\section{Growth of Mycobacterium johnei in modified Tween Liquoid-treated bovine serum medium}

Eight strains of $M$. johnei were available for examination. Two were from the A.R.C. Field Station, Compton, one from the Royal Veterinary College, Streatley, three were isolated at Mill Hill during 1939-40, one was from a recent case of Johne's disease in Cheshire, and one was a sheep strain. They were maintained on Dunkin's medium or on a modification of Herrold's egg yolk agar containing $M$. phlei. On the latter medium the rate of growth is slower but the agar base has the advantage that it is firmer than ordinary egg medium and therefore more suitable when weighed amounts of culture are required.

The observations of Davis \& Dubos (1948) and of Taylor (1950) that $M$. johne $i$ will not grow in Tween medium were confirmed; in addition, attempts to cultivate the strains in L.T.s. medium, which was most satisfactory for $M$. tuberculosis, were unsuccessful. $M$. johnei, when first isolated, will not grow on egg media or on the surface of liquid media in the absence of growthpromoting factors present in acid-fast bacilli: consequently these results were not unexpected. Davis \& Dubos (1948) have reported that small amounts of an extract of $\boldsymbol{M}$. phlei enhance the growth of $\boldsymbol{M}$. tuberculosis, but that larger amounts have an inhibitory effect. $M$. johnei failed to grow in Tween 80 plus albumin $\mathrm{V}$ enriched with extract of $M$. phlei.

It was hoped that a glycerol extract of $M$. phlei (Taylor, 1950) would enable $M$. johnei to multiply in L.T.S. medium and such proved to be the case. A 7-day surface growth of $\boldsymbol{M}$. phlei from a $250 \mathrm{ml}$. flask of $5 \%$ glycerol broth was steamed. The bacterial mass was washed several times, reduced to a fine pulp and taken up in $80 \mathrm{ml}$. of distilled water and $20 \mathrm{ml}$. glycerol. The suspension was autoclaved, centrifuged, and the supernatant fluid added to the basal medium before sterilization. Preliminary experiments showed that L.T.S. medium enriched with the phlei extract was satisfactory for the growth of some strains of $M$. johnei when the proportion was not in excess of $4 \%$ or less that $1 \%$ (Table 6). Large amounts of the extract may inhibit growth either by the phlei extract interfering with the protective action of the serum against the breakdown of the Tween 80, as suggested by Dubos, or by the effect of higher concentrations of glycerol in preventing growth.

Multiplication of $M \cdot$ johne $i$ in the medium is slow and in primary cultures a visible turbidity may not develop before the 10th to 14th day but, after several subcultures, the rate of growth is accelerated.

Medium sterilized by heating on 3 successive days was less satisfactory than medium sterilized by filtration. Moreover, the improvement in the rate of growth in unheated medium became more marked on subcultivation. In 
continuous subcultivation, growth was always slower than $M$. tuberculosis and never reached the same maximum intensity (Table 6). There were differences in the ability of the various strains to adapt themselves to the new medium; one strain (R.V.C.), well trained to grow on solid medium, and one recently isolated strain $(\mathrm{H})$ gave a moderate turbidity after 21-29 days in the primary cultures and in the succeeding five passages, but subsequently reached their maximum growth in 12-15 days. One Compton and two Mill Hill strains were more difficult to adapt and were still less active. The other strains, including that from the sheep, have so far failed to show any appreciable growth.

Table 6. Growth of Mycobacterium johnei in basic medium plus glycerol extract of M. phlei

\begin{tabular}{|c|c|c|}
\hline \multirow{2}{*}{$\begin{array}{c}\text { Glycerol extract } \\
\%(v / v)\end{array}$} & \multicolumn{2}{|c|}{ Growth (mg./ml.) at 15th day } \\
\hline & Strain R.V.C.* & Strain $\mathbf{H} \dagger$ \\
\hline $6 \cdot 0$ & $0 \cdot 2$ & tr. \\
\hline $4 \cdot 0$ & 0.5 & $0 \cdot 3$ \\
\hline $\mathbf{2 \cdot 0}$ & $0 \cdot 4$ & $0 \cdot 2$ \\
\hline $1 \cdot 0$ & $0 \cdot 2$ & tr. \\
\hline $0 \cdot 5$ & tr. & tr. \\
\hline None & 一 & 一 \\
\hline
\end{tabular}

The fluid usually shows a uniform turbidity but from time to time the growth has become somewhat granular. This change in the character of the dispersed growth seems to be related to certain batches of serum and the cause is unknown. In stained smears the bacilli are not completely dispersed but appear as aggregates varying from 4 to $\mathbf{3 0}$ organisms. The bacilli are slightly longer than those from solid medium and may present a beaded appearance.

\section{DISCUSSION}

The fundamental studies of Dubos and his co-workers have shown that when a small amount of purified albumin is added to a suitable defined medium containing Tween 80 (a water-soluble ester of oleic acid), M. tuberculosis grows rapidly in a dispersed form rather than as a pellicle. In the present investigation it has been demonstrated that the rate of growth of the tubercle bacillus can be accelerated by substituting for fraction $V$ albumin the supernatant portion of serum treated with Liquoid. Dubos \& Davis (1946) believe that as Tween 80, in concentrations higher than those recommended for their medium, has a powerful inhibitory action on the multiplication of the tubercle bacillus and as this effect can be overcome by suitable amounts of serum albumin, the latter probably protects micro-organisms against the toxic action of the fatty acids liberated from Tween 80 . They suggest that the sparing action of the albumin is the important factor and that there is no evidence of any growth-promoting fraction in the serum. It is possible that the fraction 
obtained from Liquoid-treated serum has a purely passive effect similar to that of serum albumin. On the other hand, Dubos \& Davis have recorded poor growths of acid-fast organisms in Tween medium containing other proteins such as gelatin, serum globulin and casein, which they attribute to the failure of these substances to protect the bacilli against the toxic effects of free oleic acid. If this is the case, one would expect that the sediment from Liquoid-treated serum, which appears to contain nearly all the albumin, would be as effective as fraction $\mathrm{V}$ albumin. In fact, it fails entirely to support growth in Tween medium whereas the supernatant fluid, which contains a high proportion of euglobulin and some pseudoglobulin, is fully active. The suitability of the latter fraction might still be ascribed to a sparing action similar to that exerted by albumin, but it would seem equally likely that it contains substances which favour the multiplication of the tubercle bacillus.

A highly purified sample of ferrous ammonium citrate did not improve the rate of growth but was effective in the presence of Yeastrel, whereas a less pure iron salt did not require the addition of Yeastrel. It is possible, therefore, that other elements, such as copper, may be necessary for growth.

The strains of $M$. johnei, which infect cattle, generally grow on a variety of complex egg media containing extracts of acid-fast bacilli. The slow rate of development is a drawback in the study of this group, but as the tubercle bacillus multiplies rapidly in Dubos medium, it was hoped that by adding extracts of $M$. phlei, $M$. johnei would grow in dispersed form. The surprising observation of other workers that such is not the case has been confirmed. The new medium described in this paper is, however, suitable for some strains, irrespective of the period during which they have been grown on conventional media, whereas other strains have so far defied all attempts at adaptation. This observation on resistance to cultivation may be due to strain variations and would fall into line with the findings of Taylor (1945) that some strains are apparently uncultivatable on egg media.

It is clear that the modified medium described is unlikely to be of value in the isolation of Johne's bacillus from natural material, as strains well adapted to artificial cultivation still require several passages in Dubos medium. On two occasions tissues rich in $M$. johne $i$ have been treated with $\mathrm{KOH}$, washed and transferred to the new medium: no evidence of multiplication has been detected.

I am indebted to Mr R. J. Garner, Department of Biochemistry, University of Liverpool, for the analyses of the sample of Liquoid-treated serum, and to Roche Products Ltd., Welwyn Garden City, Herts, for generous supplies of Liquoid.

The investigation has been aided by a grant from the Agricultural Research Council.

\section{REFERENCES}

Atlgöwer, M. (1949). Die Wirkung von Kalzium und Serum auf Wanderung von Zitrat geschadigten menschlichen Leukozyten. Experientia, 5, 405.

Belyavin, G., Westwood, J. C. N., Please, N. W. \& Smith, W. (1951). Influenza haemagglutination. An evaluation of the photoelectric titration method. J. gen. Microbiol. 5, 546. 
Chorine, V. (1941). Mode d'action du liquoïde dans la coagulation du sang. C.R. Soc. biol., Paris, 135, 451.

Davis, B. D. \& DuBos, R. J. (1946). Interaction of serum albumin, free and esterified oleic acid and lipase in relation to the cultivation of the tubercle bacillus. Arch. Biochem. 11, 201.

Davis, B. D. \& Duros, R. J. (1948). The inhibitory effect of lipase on bacterial growth in media containing fatty acid esters. $J$. Bact. 55, 11.

Dubos, R. J. (1947). The effects of lipids and serum albumin on bacterial growth. J. exp. Med. 85, 9.

Dubos, R. J. \& Davis, B. D. (1946). Factors affecting the growth of tubercle bacilli in liquid media. J. exp. Med. 83, 409.

Dubos, R. J. \& Middlebrook, G. (1948). The effect of wetting agents on the growth of tubercle bacilli. J. exp. Med. 88, 81 .

HAEBLER, 'T. von \& MrLes, A. A. (1938). The action of sodium polyanethol sulphonate ('liquoid') on blood cultures. J. Path. Bact. 46, 245.

Hoare, E. D. (1939). The suitability of 'liquoid' for use in blood culture media, with particular reference to anaerobic streptococci. J. Path. Bact. 48, 573.

Holden, J. van DER (1940). Application of phagocytosis in diagnosis of brucellosis: use of citrate and liquoid. Tijdschr. Diergeneesk. 67, 910.

Paterson, A. B. \& Winmill, A. J. (1950). Note on use of Dubos medium for cultivation of Mycobact. tuberculosis from milk. J. comp. Path. 60, 219.

Stuart, R. D. (1948). Value of liquoid for blood culture. J. clin. Path. 1, 311.

TAYLor, W. (1945). Ovine paratuberculosis (Johne's disease of sheep). J. comp. Path. 55, 41.

TAYLOR, W. (1950). Observations on the isolation of Mycobacterium johnei in primary culture. J. Path. Bact. 62, 647.

(Received 28 August 1951) 